\title{
Erratum to: Oncomirs miRNA-221/222 and Tumor Suppressors miRNA-199a/195 Are Crucial miRNAs in Liver Cancer: A Systematic Analysis
}

\author{
Yanhu $\mathrm{Li}^{1,3}$ - Chunhong $\mathrm{Di}^{2} \cdot$ Wen $\mathrm{Li}^{4} \cdot$ Weibin $\mathrm{Cai}^{2} \cdot \mathrm{Xiaohua} \mathrm{Tan}^{2}$. \\ Liangwen $\mathrm{Xu}^{2} \cdot$ Lei Yang ${ }^{2}$ Guoqiang $\mathrm{Lou}^{2} \cdot$ Yutao $\mathrm{Yan}^{2,3}$
}

Published online: 26 August 2016

(C) Springer Science+Business Media New York 2016

\section{Erratum to: Dig Dis Sci (2016) 61:2315-2327 \\ DOI 10.1007/s10620-016-4156-8}

The original version of this article is inadvertently published without mentioning the funding information. The missing information is given below.

Acknowledgments This work was supported by grants from the Natural Science Foundation of China (81570479), the Climbing Program in Hangzhou Normal University-Phase II (PF14002004021), and the Hangzhou City Health Bureau Project (2013A19).

The online version of the original article can be found under doi:10.1007/s10620-016-4156-8.

Guoqiang Lou

Louguoqiang2012@126.com

$\triangle$ Yutao Yan

yutaoyan@yahoo.com

1 College of Life Science, Shihezi University, 48 Dongmingxin

St., Urumqi 830011, Xinjiang, People's Republic of China

2 Affiliated Hospital, Hangzhou Normal University, 126 Wenzhou St., Hangzhou 310015, Zhejiang, People's Republic of China

3 School of Medicine, Hangzhou Normal University, 16 Xuelin Road, Xiasha Higher Education Park,

Hangzhou 310036, Zhejiang, People's Republic of China

4 IHRC Inc., 2 Ravinia Drive, Suite 1750, Atlanta, GA 30346, USA 